\title{
Frantz Grenet. "The Circulation of Astrological Lore and Its Political Use between the Roman East, Sasanian Iran, Central Asia, India and the Türks"
}

\section{Alessia Zubani}

\author{
(2) OpenEdition \\ Journals \\ Édition électronique \\ URL : http://journals.openedition.org/abstractairanica/51023 \\ DOI : 10.4000/abstractairanica.51023 \\ ISBN : 1961-960X \\ ISSN : 1961-960X \\ Éditeur : \\ CNRS (UMR 7528 Mondes iraniens et indiens), Éditions de l'IFRI
}

Référence électronique

Alessia Zubani, « Frantz Grenet. "The Circulation of Astrological Lore and Its Political Use between the Roman East, Sasanian Iran, Central Asia, India and the Türks" », Abstracta Iranica [En ligne], Volume 40-41 | 2019, document 5, mis en ligne le 30 décembre 2019, consulté le 19 avril 2021. URL : http:// journals.openedition.org/abstractairanica/51023; DOI : https://doi.org/10.4000/abstractairanica. 51023

Ce document a été généré automatiquement le 19 avril 2021

Tous droits réservés 


\title{
Frantz Grenet. "The Circulation of Astrological Lore and Its Political Use between the Roman East, Sasanian Iran, Central Asia, India and the Türks"
}

\author{
Alessia Zubani
}

\section{RÉFÉRENCE}

Frantz Grenet. "The Circulation of Astrological Lore and Its Political Use between the Roman East, Sasanian Iran, Central Asia, India and the Türks" in Nicola di Cosmo, Michael Maas (eds.). Empires and Exchanges in Eurasian Late Antiquity Rome, China, Iran, and the Steppe, ca. 250-750. Cambridge, New York: Cambridge University Press, 2018, p. 235-252

1 L'astrologie révèle son rôle imposant dans les discours sociaux et politiques développés dans le monde eurasiatique de l'Antiquité tardive et de la première époque islamique. L'A. se penche sur le rôle de l'astrologie à la cour sassanide et sur son rapport avec les représentants sacerdotaux de la religion zoroastrienne. La rareté des informations autant textuelles que matérielles - ne nous permet pas de saisir le poids réel de l'influence des astrologues dans le milieu de la cour pour résoudre des questions d'ordre social, politique et militaire. Néanmoins, c'est à l'école astrologique sassanide qu'on doit le travail de systématisation des savoirs greco-égyptiens, babyloniens et indiens. L'A. montre aussi comment les données provenant de l'Asie centrale peuvent aider à mieux centrer le rôle de l'astrologie sassanide dans les discours développés dans la première époque islamique, ainsi que sa contribution dans la formation des savants (Abū Ma'shar, parmi les autres). Enfin, l'A. remarque l'utilisation des éléments 
astrologiques dans les discours légitimatoires des entités politiques de l'Asie centrale qui se faisaient fort de l'héritage iranien ancien.

\section{AUTEURS}

\section{ALESSIA ZUBANI}

Doctorante EPHE, Mondes iranien et indien, Paris 